\title{
Reactivity of Monoterpene Criegee Intermediates at Gas-Liquid Interfaces
}

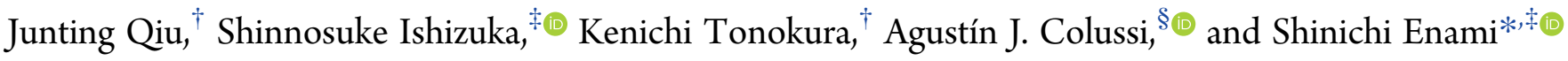 \\ ${ }^{\dagger}$ Graduate School of Frontier Sciences, The University of Tokyo, 5-1-5 Kashiwanoha, Kashiwa 277-8563, Japan \\ ${ }^{\ddagger}$ National Institute for Environmental Studies, 16-2 Onogawa, Tsukuba 305-8506, Japan \\ ${ }^{\S}$ Ronald and Maxine Linde Center for Global Environmental Science, California Institute of Technology, Pasadena, California \\ 91125, United States
}

Supporting Information

ABSTRACT: Biogenic monoterpenes are major sources of Criegee intermediates (CIs) in the troposphere. Recent studies underscored the importance of their heterogeneous chemistry. The study of monoterpene CI reactions on liquid surfaces, however, is challenging due to the lack of suitable probes. Here, we report the first mass spectrometric detection of the intermediates and products, which include labile hydroperoxides, from reactions of CIs of representative monoterpenes ( $\alpha$-terpinene, $\gamma$-terpinene, terpinolene, D-limonene, $\alpha$-pinene) with water, cis-pinonic acid (CPA) and octanoic acid (OA) on the surface of liquid microjets. Significantly, the relative yields of $\alpha$-hydroxy-hydroperoxides production from CIs hydration at the gas-liquid interface- $\alpha$-terpinene $(1.00) \gg$ D-limonene $(0.18)>\gamma$ terpinene $(0.11) \sim$ terpinolene $(0.10) \gg \alpha$-pinene $(0.01)$ - do not track the rate constants of their gas-phase ozonolyses. Notably, in contrast with the inertness of the other CIs, the CIs derived from $\alpha$-terpinene ozonolysis readily react with CPA and OA to produce $\mathrm{C}_{20}$ and $\mathrm{C}_{18}$ ester hydroperoxides, respectively. Present results reveal hitherto unknown structural effects on the reactivities of CIs at aqueous interfaces.

\section{INTRODUCTION}

Biogenic monoterpenes emissions from vegetation and microorganisms are leading sources of volatile organic compounds (VOCs) in the troposphere. ${ }^{1,2}$ By possessing one or two $\mathrm{C}=\mathrm{C}$ bonds, ozonolyses is a major sink for monoterpenes, which yields reactive carbonyl oxide diradicals (or zwitterions) known as Criegee intermediates (CIs). ${ }^{3,4}$ About $\sim 80 \%$ of the CI source strength in the Sierra Nevada region of United States derives from monoterpenes and related compounds, whereas in the Amazonian forest the major contributor to CIs is isoprene. ${ }^{5}$ CIs are important because they participate in the HOx cycle and in particle formation. ${ }^{6-13}$ Reported CIs concentrations in the boundary layer reach $\sim(1-5) \times 10^{4}$ molecules $\mathrm{cm}^{-3} .^{14}$ Independent studies estimated annual average $<7 \times 10^{3}$ CIs molecules $\mathrm{cm}^{-3}$ concentrations. ${ }^{5}$ In some regions (e.g., the equatorial belt), CIs are involved in the formation of sulfuric acid and the removal of oxygenated species. ${ }^{5}$ The fact that the dominant reaction partner for the smallest $\mathrm{CI}\left(\mathrm{CH}_{2} \mathrm{O}_{2}\right)$ under ambient conditions is the water dimer $\left(\mathrm{H}_{2} \mathrm{O}\right)_{2}{ }^{6}$ might suggest, by analogy, a similar fate for most gaseous CIs. ${ }^{5}$ Lin and co-workers, however, have argued that CI reactivity could critically depend on structure. Therefore, the atmospheric fate of the larger and more relevant CIs could involve different processes. ${ }^{6}$

The high reactivity of CIs and some of their reaction products poses serious difficulties to experimental studies. As a

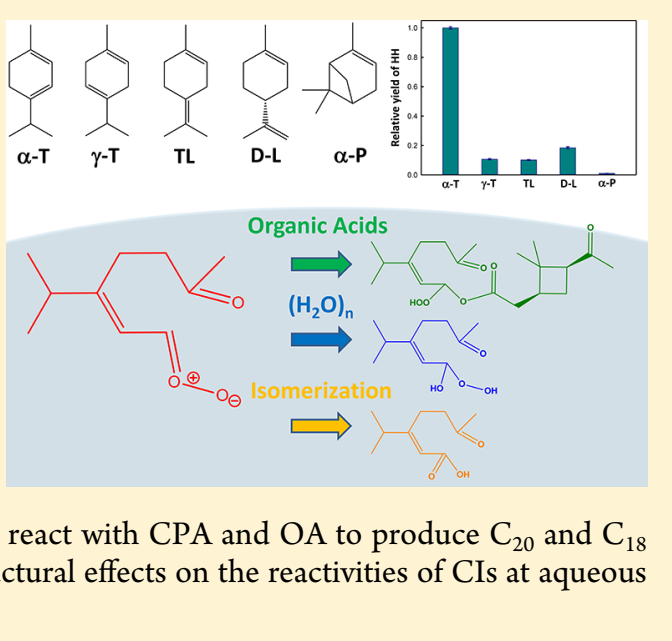

result, there is a paucity of information on the kinetics and mechanisms of reactions of atmospherically relevant monoterpene CIs. An important consideration is that CIs are not only produced and react in the gas-phase. Recent studies have brought attention to the importance of CI chemistry at the gas-liquid interface of tropospheric aerosols. Enami et al. found that sesquiterpene CIs react with carboxylic acids, alcohols, and saccharides at the gas-liquid interface, in competition with a large excess of water. ${ }^{15-18}$ Remarkably, they showed that $\mathrm{mM}$ acidic, surface-active hydroxylic species compete with water molecules in the outermost interfacial layers of aqueous organic aerosols. ${ }^{15-18} \mathrm{~A}$ key experimental finding was that, in the presence of inert $\mathrm{NaCl}$, labile and neutral organic hydroperoxide products could be detected by mass spectrometry as chloride adducts. ${ }^{15-18}$ The implications of these results are that CIs can bypass water on the surface of aqueous organic aerosols and produce oligomers of extremely low volatility that contribute to the growth of atmospheric particles. Theoretical studies by Francisco and co-workers showed that $\mathrm{CH}_{2} \mathrm{O}_{2}$ reacts $\sim 10^{2}-10^{3}$ times faster at the air/ water interface than in the gas-phase, but large CIs are rather

Received: July 18, 2018

Revised: August 22, 2018

Published: September 5, 2018 

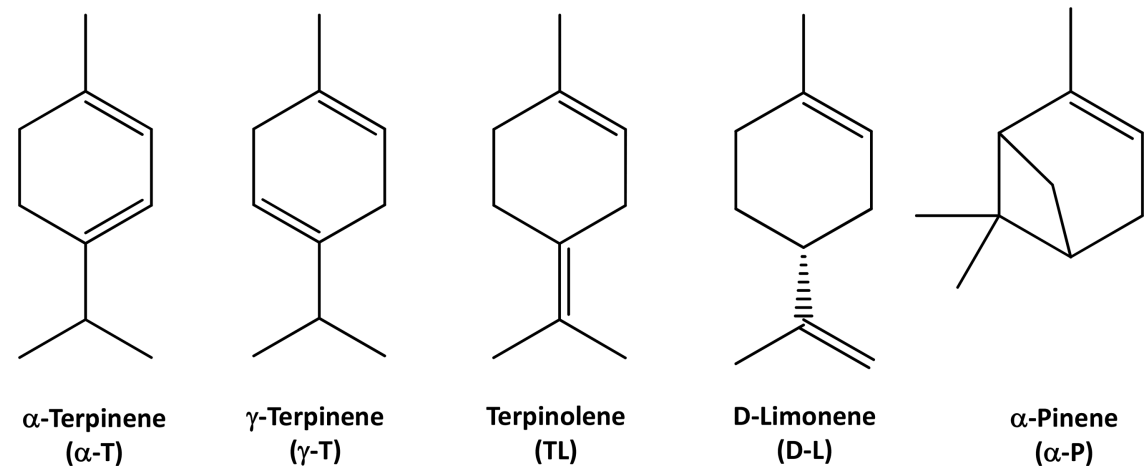

Figure 1. Chemical structures of monoterpenes $\left(\mathrm{C}_{10} \mathrm{H}_{16}, \mathrm{MW}=136.23\right)$ used in the present study.

inert toward water molecules. ${ }^{19-21}$ These interesting predictions remain to be confirmed experimentally.

Globally, $\alpha$-pinene, $\beta$-pinene, and limonene are emitted at 66.1, 18.9, and $11.4 \mathrm{Tg}$ /year, respectively. ${ }^{1}$ Although the fate of monoterpenes has been deemed to be controlled by gasphase reactions, ${ }^{22}$ recent studies revealed that the dry deposition of gaseous monoterpenes onto acidic surfaces may be competitive with their gas-phase processing, particularly over dense forest canopies. ${ }^{23,24}$ There is evidence of the formation of unsaturated oligomers during the uptake of isoprene and monoterpenes on acidic surfaces, ${ }^{23-28}$ where they can react with $\mathrm{O}_{3}(\mathrm{~g})$ to generate CIs in situ. The potential importance of the heterogeneous chemistry of tropospheric CIs raised by these studies has not yet been matched by direct experimental studies, mainly by the lack of appropriate methodologies.

Here we report the first-time detection of products and intermediates from the reactions of CIs generated on the fresh surfaces of a series of monoterpenes in water:acetonitrile (W:AN) or water:tetrahydrofuran (W:THF) solution microjets upon exposure to $\mathrm{O}_{3}(\mathrm{~g})$ for $\sim 10 \mu$ s (Figure $\mathrm{S} 1$ ). We chose five representative monoterpenes: $\alpha$-terpinene $(\alpha-\mathrm{T}), \gamma$ terpinene $(\gamma-\mathrm{T})$, terpinolene (TL), D-limonene (D-L), and $\alpha$ pinene $(\alpha-\mathrm{P})$ (Figure 1). Their typical tropospheric lifetimes toward ozonolyses are $\sim 1,170,13,120$, and $280 \mathrm{~min}$, respectively. ${ }^{22}$ The surfaces of $\mathrm{W}: \mathrm{AN}$ and W:THF mixtures $^{29-31}$ are considered to be realistic surrogates of atmospheric aqueous organic media. Here, by detecting reaction intermediates that include potentially labile hydroperoxides, we are able to elucidate the role of monoterpenes structure on their mechanisms of ozonolysis, and the reactivity of the corresponding CIs with water $\left[\left(\mathrm{H}_{2} \mathrm{O}\right)_{n}\right]$, cis-pinonic acid (CPA) and octanoic acid (OA) at the gas-liquid interface for the first time.

\section{EXPERIMENTAL SECTION}

The present experimental setup, which is the same as those we reported elsewhere, ${ }^{18,32}$ is briefly described herein.. A mixture of $[$ monoterpene $+\mathrm{NaCl}]$ in $\mathrm{W}: \mathrm{AN}$ or W:THF ( vol:vol $=1: 4$ ) microjets is exposed to orthogonal gas-phase $\mathrm{O}_{3} / \mathrm{O}_{2}$ streams in the reaction chamber of a mass spectrometer (ES-MS, Agilent 6130 Quadrupole LC/MS Electrospray System at NIES, Tsukuba) flushed with $\mathrm{N}_{2}(\mathrm{~g})$ at $1 \mathrm{~atm}, 298 \mathrm{~K}$ (Figure $\mathrm{S} 1$ ).

The observed mass spectra correspond to ionic reactants/ products in the outermost interfacial layers of the liquid microjets detected within $\sim 1 \mathrm{~nm}$, as confirmed by numerous previous experiments. ${ }^{32-35}$ For example, in our experiments involving hexanoic acid $(\mathrm{PCOOH})$ dissolved in $\mathrm{H}_{2} \mathrm{O} / \mathrm{D}_{2} \mathrm{O}$ microjets exposed to $\mathrm{HNO}_{3}(\mathrm{~g})$ or $\mathrm{DNO}_{3}(\mathrm{~g})$, we found that the $\mathrm{H} / \mathrm{D}$ labels of the $\mathrm{PCOOH}_{2}{ }^{+}, \mathrm{PCOOHD}^{+}$, and $\mathrm{PCOOD}_{2}{ }^{+}$ products detected by mass spectrometry were determined by isotope scrambling in outermost interfacial layers of $\sim 1 \mathrm{~nm}$ thickness rather than in the bulk phase of the microjets. ${ }^{36}$ The fast ozonolyses of the monoterpenes used in the present study are expected to proceed in similarly thin interfacial nanolayers. We have also shown that terpenes are ozonolyzed on the surface of the intact microjet rather than on the surface of the microdroplets produced upon its nebulization. ${ }^{37}$ Relatively small ozone exposures: $E=\left[\mathrm{O}_{3}(\mathrm{~g})\right] \times \tau_{\mathrm{R}} \leq 5.4 \times 10^{11}$ molecules $\mathrm{cm}^{-3} \mathrm{~s}$ are compatible with monoterpene ozonolyses on liquid surfaces within very short $\sim 10 \mu \mathrm{s}$ contact times. $\mathrm{W}: \mathrm{AN}$ or W:THF solutions containing a monoterpene and

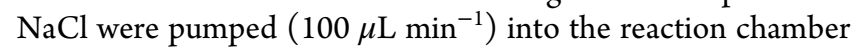
through a grounded stainless steel needle (100 $\mu \mathrm{m}$ bore) while nebulizer $\mathrm{N}_{2}(\mathrm{~g})$ flowed through a coaxial at a high gas velocity $\left(v_{\mathrm{g}} \approx 160 \mathrm{~m} / \mathrm{s}\right) .^{38,39}$ Chloride anion $\left(\mathrm{Cl}^{-}\right)$was found to be unreactive toward $\mathrm{O}_{3}(\mathrm{~g})$ under present conditions. ${ }^{18}$ Further experimental details could be found in previous publications. $18,32,33,39,40$

Ozone was prepared by flowing $\mathrm{O}_{2}(\mathrm{~g})$ (>99.999\%) through a commercial ozonizer (KSQ-050, Kotohira, Japan). Exposure values $\left(E=\left[\mathrm{O}_{3}(\mathrm{~g})\right] \times\right.$ time $)$ are derived from $\left[\mathrm{O}_{3}(\mathrm{~g})\right]$ measured by a UV-vis spectrometer (Agilent 8453), as diluted by the drying nitrogen gas, and the lifetime of the intact microjets. Conditions in the present experiments were as follows: drying nitrogen gas flow rate, $12 \mathrm{~L} \mathrm{~min}^{-1}$; drying nitrogen gas temperature, $340{ }^{\circ} \mathrm{C}$; inlet voltage, $+3.5 \mathrm{kV}$ relative to ground; fragmentor voltage value, $60 \mathrm{~V}$. All solutions were prepared in purified water (resistivity $\geq 18.2$ $\mathrm{M} \Omega \mathrm{cm}$ at $298 \mathrm{~K}$ ) from a Millipore Milli-Q water purification system and used within a couple of days. Chemicals: $\alpha$ terpinene ( $>90.0 \%$, Tokyo Chemical Industry), $\gamma$-terpinene (>95.0\%, Tokyo Chemical Industry), terpinolene (>85.0\%, Tokyo Chemical Industry), (+)-limonene (>99.0\%, Tokyo Chemical Industry), (-)- $\alpha$-pinene ( $\geq 95 \%$, Wako), cis-pinonic acid ( $\geq 98 \%$, Sigma-Aldrich), octanoic acid (>97.0\%, Wako), acetonitrile ( $\geq 99.8 \%$, Wako), tetrahydrofuran ( $\geq 99.8 \%$, stabilizer free, Wako), $\mathrm{D}_{2} \mathrm{O}$ (>99.9 atom \% D, Sigma-Aldrich), $\mathrm{H}_{2}{ }^{18} \mathrm{O}$ (97\%, Santa Cruz Biotechnologies), and $\mathrm{NaCl}$ ( $\geq 99.999 \%$, Sigma-Aldrich) were used as received.

\section{RESULTS AND DISCUSSION}

Figure 2 shows negative ion mass spectra of $(1 \mathrm{mM} \alpha-\mathrm{T}+0.2$ $\mathrm{mM} \mathrm{NaCl})$ in $\mathrm{W}: \mathrm{AN}(1: 4=\mathrm{vol}: \mathrm{vol})$ solution microjets in the absence and presence of $\mathrm{O}_{3}(\mathrm{~g})$. 


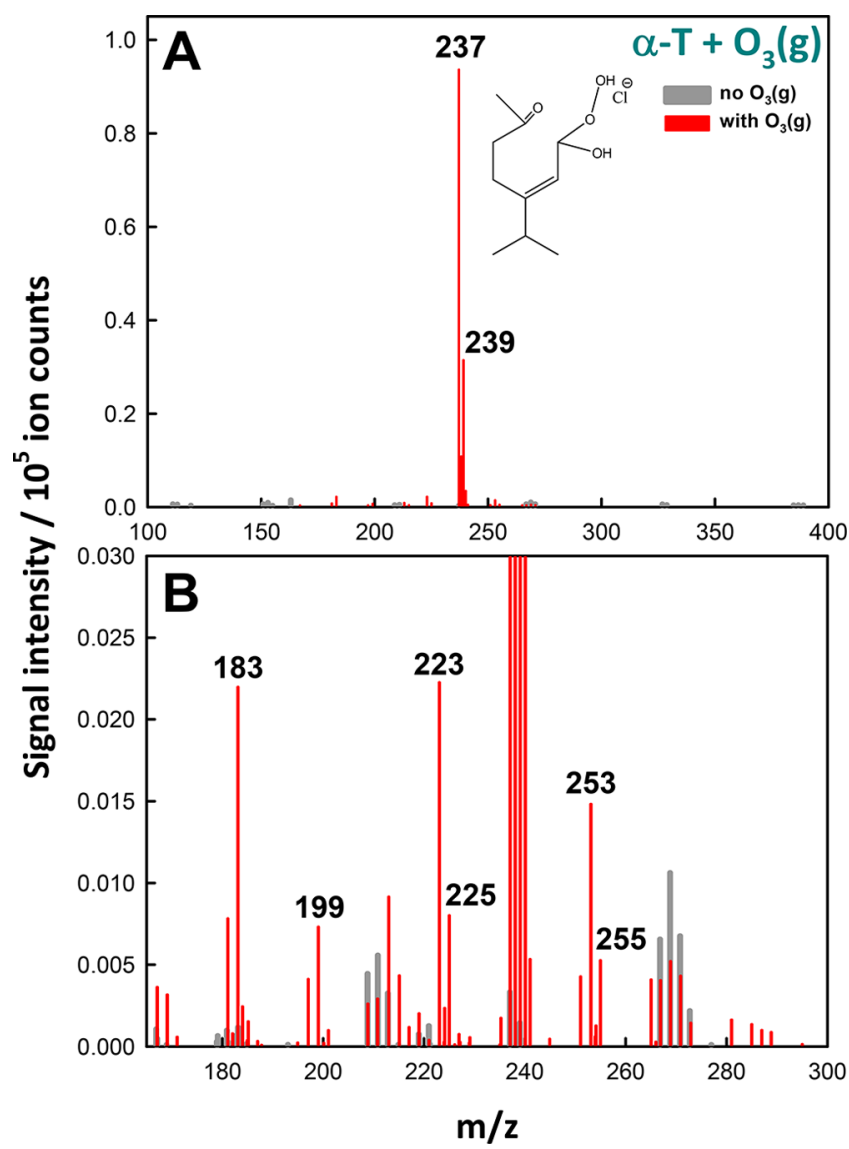

Figure 2. (A) Negative ion mass spectra of $1 \mathrm{mM} \alpha$-terpinene +0.2 $\mathrm{mM} \mathrm{NaCl}$ in W:AN (1:4 = vol:vol) solution microjets (gray), and during exposure to $\mathrm{O}_{3}(\mathrm{~g})\left(\mathrm{red}, \mathrm{E}=4.3 \times 10^{11}\right.$ molecules $\mathrm{cm}^{-3} \mathrm{~s}$ ) at 1 atm and $298 \mathrm{~K}$. The $\mathrm{m} / z$ 237;239 signals correspond to chlorideadducts of $\alpha$-hydroxy-hydroperoxides (HH). (B) Zooming-in on minor products. A representative structure of the $\mathrm{HH}-\mathrm{Cl}^{-}$adducts is shown among possible isomers.

Upon $\mathrm{O}_{3}(\mathrm{~g})$ exposure, intense peaks appear at $\mathrm{m} / z 237 ; 239$ in the characteristic $\mathrm{M} /(\mathrm{M}+2)=3 / 1={ }^{35} \mathrm{Cl} /{ }^{37} \mathrm{Cl}$ ratio of natural abundance chlorine (Figure $2 \mathrm{~A}$ ), in addition to minor products (Figure $2 \mathrm{~B}$ ). The $\mathrm{m} / z$ 237;239 signals are therefore assigned to the chloride-adducts of the hydroxy-hydroperoxides $(\mathrm{HH})$ formed in the reaction of CIs with interfacial water: $136(\alpha-\mathrm{T})+48\left(\mathrm{O}_{3}\right)+18\left(\mathrm{H}_{2} \mathrm{O}\right)+35 ; 37\left(\mathrm{Cl}^{-}\right)=$ $237 ; 239$ (Scheme 1). ${ }^{18}$ The same major and minor products are observed from experiments in W:THF ( $1: 4=$ vol:vol) solution microjets in the presence of $\mathrm{O}_{3}(\mathrm{~g})$ (Figure S2). To our knowledge, this is the first-time that $\mathrm{HH}$ produced from monoterpene $\mathrm{CIs}+$ water reactions on liquid surfaces are detected online by mass spectrometry without further handling. Note that $\mathrm{HH}$ signal intensities are $>40$ times larger than those of other products, thereby implying that interfacial water is the dominant reactant for the CIs derived from $\alpha$ terpinene under present conditions. The $\mathrm{m} / z 183$ and 199 products are functional carboxylates detected as such (see Scheme 1), whereas the $\mathrm{m} / z 223 ; 225$ and $253 ; 255$ products are chloride adducts of neutral species (see below).

Isotopic labeling studies provided confirmation of our functional assignments. Figure 3 and Figure $S 3$ show negative ion mass spectra of $1 \mathrm{mM} \alpha-\mathrm{T}+0.2 \mathrm{mM} \mathrm{NaCl}$ in $\mathrm{D}_{2} \mathrm{O}$ :AN ( $1: 4=$ vol:vol) and in $\mathrm{H}_{2}{ }^{18} \mathrm{O}: \mathrm{AN}(1: 4)$ solution microjets, respectively, in the presence of $\mathrm{O}_{3}(\mathrm{~g})$.
Scheme 1. Reaction Scheme of $\alpha$-Terpinene CI at the GasLiquid Interface ${ }^{a}$

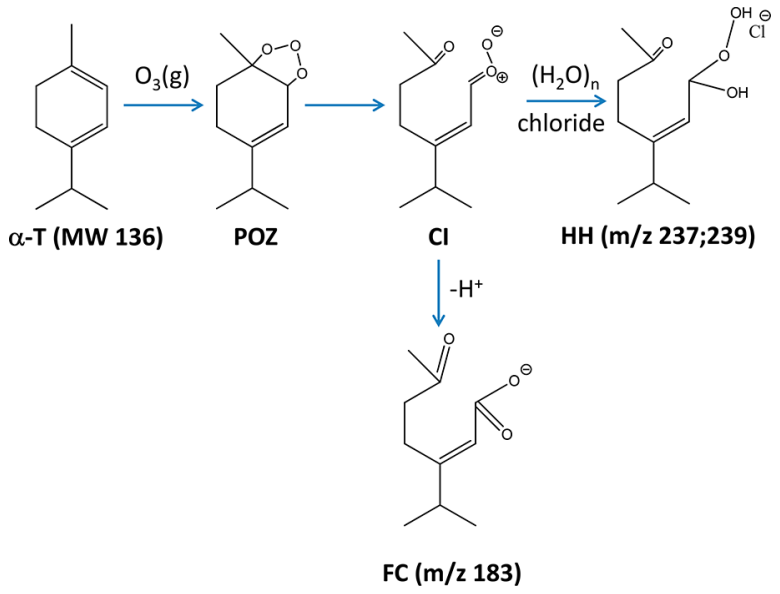

${ }^{a}$ Here we show representative structures among other possible isomers.

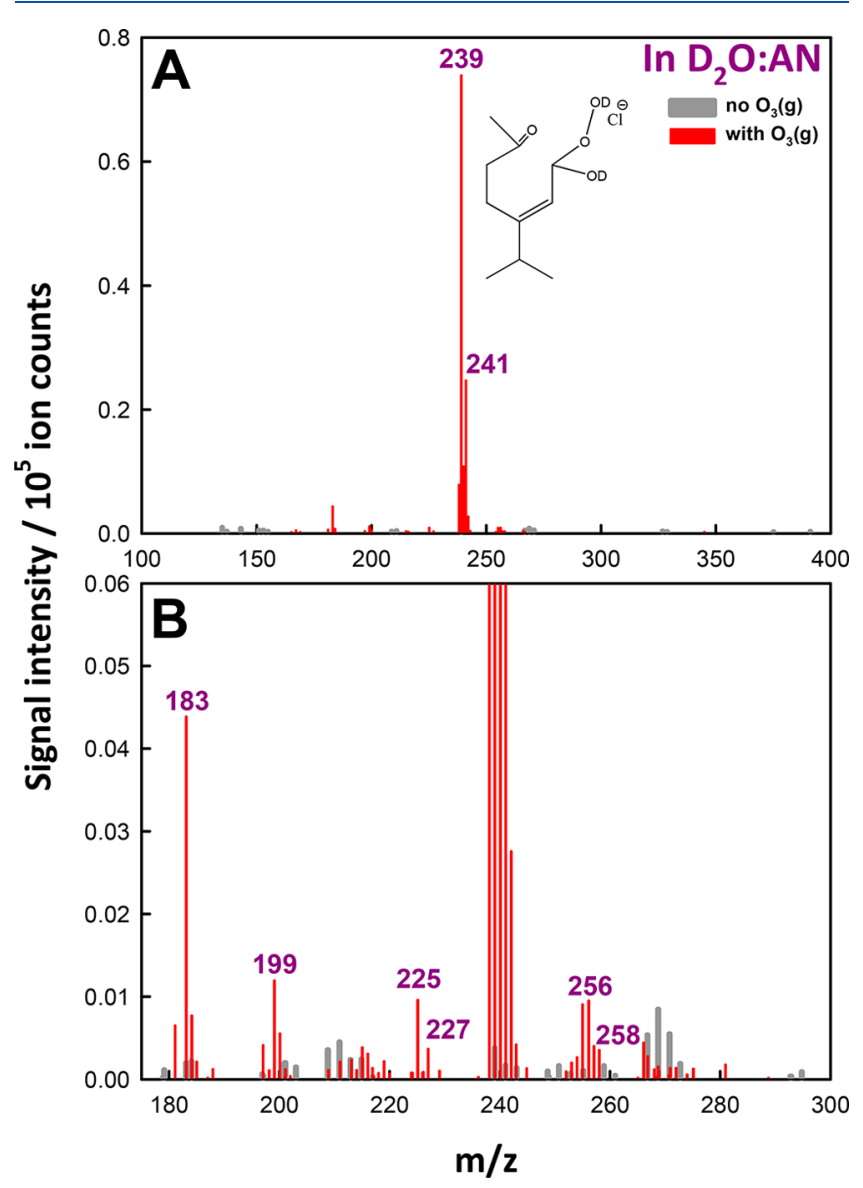

Figure 3. Negative ion mass spectra of $1 \mathrm{mM} \alpha$-terpinene $+0.2 \mathrm{mM}$ $\mathrm{NaCl}$ in $\mathrm{D}_{2} \mathrm{O}: \mathrm{AN}(1: 4=$ vol:vol) solution microjets (gray), or those exposed to $\mathrm{O}_{3}(\mathrm{~g})\left(\mathrm{red}, \mathrm{E}=3.2 \times 10^{11}\right.$ molecules $\mathrm{cm}^{-3} \mathrm{~s}$ ) at $1 \mathrm{~atm}$ and $298 \mathrm{~K}$. A representative structure of the $\mathrm{HH}-\mathrm{Cl}^{-}$adducts is shown among possible isomers.

The observation that the $m / z=237 ; 239$ signals shift by +2 mass units into $239 ; 241$ signals in $\mathrm{D}_{2} \mathrm{O}: \mathrm{AN}$ and $\mathrm{H}_{2}{ }^{18} \mathrm{O}: \mathrm{AN}$ is consistent with the involvement of water in $\mathrm{HH}$ formation from $\alpha$-T CIs. ${ }^{18}$ These experiments show that labile $\mathrm{HH}$ from monoterpenes can be readily detected by mass spectrometry as 
chloride adducts, as it was in the case of sesquiterpenes. ${ }^{15-18}$ These findings are made more remarkable by the fact that mass-spectrometric detection of neutral organic hydroperoxides has been experimentally challenging. ${ }^{41-44} \mathrm{HH}$ contain thermally and photochemically reactive hydroperoxide groups $-\mathrm{OOH}$, and therefore they may trigger polymerization processes by decomposing to form radical species under ambient conditions (albeit at much longer time scales than in our experiments). ${ }^{9,41,42,45,46}$ The reactivity of $\mathrm{HH}$ also implies that the inhalation of particulate matter (PM) containing such species could trigger the generation of reactive oxygen species (ROS) in the lung epithelial lining fluid. ${ }^{47,48}$

The $m / z=183$ product signal does not shift in $\mathrm{D}_{2} \mathrm{O}: \mathrm{AN}$ (Figure 3), but leads to a $m / z \quad 185$ product in $\mathrm{H}_{2}{ }^{18} \mathrm{O}: \mathrm{AN}$ (Figure S3). This is strong evidence that the $m / z 183$ is a functional carboxylate (FC) that contains a keto-group (Scheme 1) that can exchange $\mathrm{O}$ atoms with the solvent via $-\mathrm{C}(=\mathrm{O}) \mathrm{O}^{-}+\mathrm{H}_{2}{ }^{18} \mathrm{O} \leftrightarrow-\mathrm{C}\left(={ }^{18} \mathrm{O}\right) \mathrm{O}^{-}+\mathrm{H}_{2} \mathrm{O} \cdot{ }^{49} \mathrm{We}$ previously found that the interfacial ozonolysis of $\beta$ caryophyllene and $\alpha$-humulene produce FCs containing keto groups at $m / z=M+48-1,{ }^{17,18,37}$ suggesting that the isomerization of CIs into $\mathrm{FC}^{50}$ is a common process in the interfacial ozonolysis of terpenes. The fact that, similar to the case of the $m / z 183$ product, the $m / z 199(=183+16)$ product does not shift by $\mathrm{D}_{2} \mathrm{O}$ :AN but does shift in $\mathrm{H}_{2}{ }^{18} \mathrm{O}$ :AN solvent (Figures 3 and S3) suggests a FC containing an additional $\mathrm{O}$ atom.

In contrast with the $m / z 183$ and 199 product species, the $m / z 223 ; 225$ product shifts by +2 Da both in $\mathrm{D}_{2} \mathrm{O}: \mathrm{AN}$ and $\mathrm{H}_{2}{ }^{18} \mathrm{O}$ :AN solvents. The $m / z 253 ; 255$ product shifts by +3 and $+2 \mathrm{Da}$ in $\mathrm{D}_{2} \mathrm{O}: \mathrm{AN}$ and $\mathrm{H}_{2}{ }^{18} \mathrm{O}: \mathrm{AN}$ solvents, respectively. The fact that both products appear at larger $\mathrm{O}_{3}$-exposures (see below) strongly suggests that these are secondary products generated by more extensive ozonolysis. The $\mathrm{m} / z$ 223;225 product could be assigned to a chloride-adduct of $\mathrm{C}_{9}$ ester hydroperoxides, generated from 1,6- $\mathrm{H}$ atom migration in the participating $\mathrm{CI}^{5,51}$ followed by further ozonolysis and hydration (see Scheme S1). The proposed structure, which contains two exchangeable $H(D)$ atoms and incorporates one ${ }^{18} \mathrm{O}$ atom, is consistent with the observed mass spectra in $\mathrm{D}_{2} \mathrm{O}: \mathrm{AN}$ and $\mathrm{H}_{2}{ }^{18} \mathrm{O}$ :AN solvents (Figure 3 and $\mathrm{S} 3$ ). The $\mathrm{m} / z$ $253 ; 255$ product could be formed by further oxidation of $\mathrm{HH}$, which we tentatively assign to the chloride-adduct of a $(\mathrm{HH}+$ O) species $(m / z 237 ; 239+16)$, most likely containing an aldehydic-group and an epoxide-group (Scheme S2). ${ }^{52}$

Figure 4 shows mass spectral signals derived from ( $1 \mathrm{mM} \alpha$ $\mathrm{T}+0.2 \mathrm{mM} \mathrm{NaCl})$ in $\mathrm{W}: \mathrm{AN}(1: 4)$ microjets exposed to gaseous $\mathrm{O}_{3} / \mathrm{O}_{2}$ mixtures as a function of $E\left(\mathrm{O}_{3}\right)$. The observed nonzero initial slopes for $\mathrm{HH}(\mathrm{m} / z 237)$ and $\mathrm{FC}(\mathrm{m} / z 183)$ indicate that they are primary products. In contrast, the $\mathrm{m} / z$ 223 and 253 species appear to be produced by secondary ozonolysis, in accordance with the proposed mechanism of formation. The slight decrease observed in the $\mathrm{HH}$ vs $E\left(\mathrm{O}_{3}\right)$ plot at larger $E\left(\mathrm{O}_{3}\right)$ suggests that $\mathrm{HH}$, by retaining a $\mathrm{C}=\mathrm{C}$ bond in its structure, reacts further with $\mathrm{O}_{3}$ to form the secondary products. Interestingly, the remaining $\mathrm{C}=\mathrm{C}$ bond in the FC, in contrast, is relatively unreactive, as shown by the constant FC yield as a function of $E\left(\mathrm{O}_{3}\right)$. Note that both the $\mathrm{HH}$ and $\mathrm{FC}$ would have declined at larger $E\left(\mathrm{O}_{3}\right)$ if $\mathrm{O}_{3}$ had reacted with the CIs, as in gas-phase reactions. ${ }^{53,54}$ Notably, the isomerization of CIs followed by the deprotonation into FC $(m / z 183)$ is competitive with CI hydration in the presence of a large excess of interfacial water molecules under

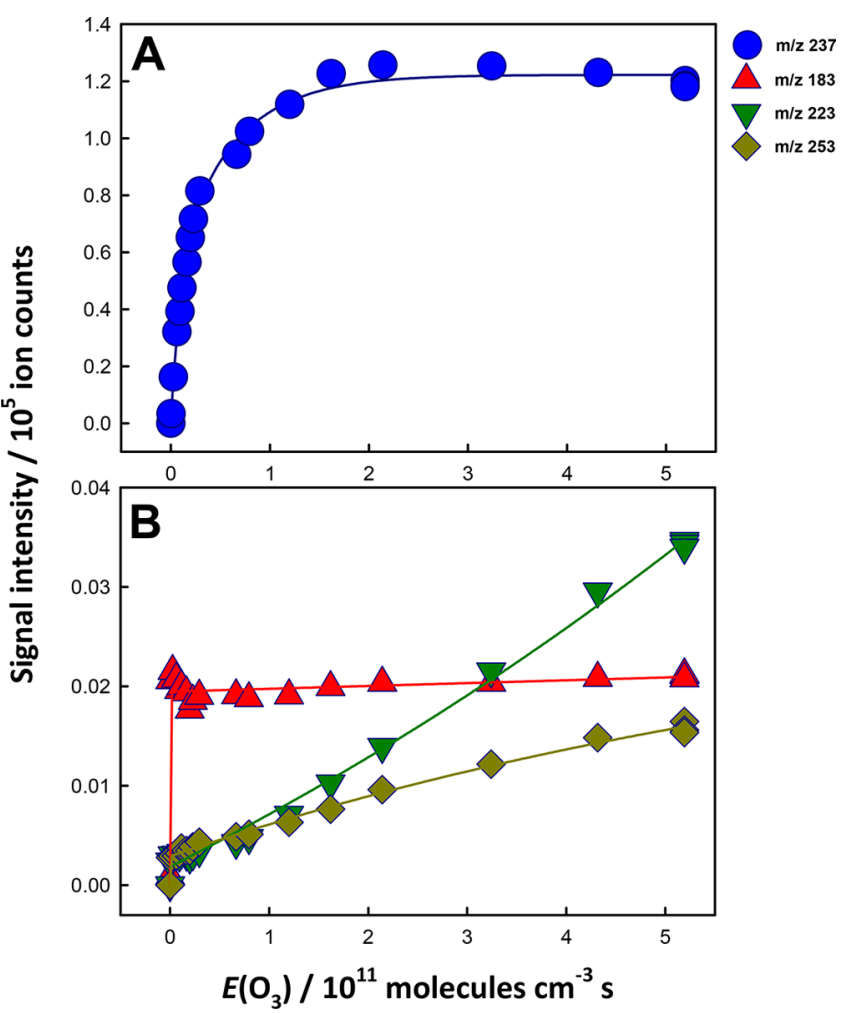

Figure 4. Mass spectral signal intensities of (A) hydroxy-hydroperoxide product $(\mathrm{m} / \mathrm{z} 237)$ and (B) minor products $(\mathrm{m} / \mathrm{z} 183,223$ and 253) from $1 \mathrm{mM} \alpha$-terpinene $+0.2 \mathrm{mM} \mathrm{NaCl}$ in W:AN (1:4 = vol:vol) solution microjets exposed to $\mathrm{O}_{3}(\mathrm{~g})$ as a function of $\mathrm{O}_{3}(\mathrm{~g})$ exposure (in $10^{11}$ molecules $\mathrm{cm}^{-3} \mathrm{~s}$ ). Connecting lines are guides to the eye.

present conditions (Figure 4). This finding confirms theoretical predictions that the competition between CI unimolecular isomerization vs bimolecular reaction with water vapor is strongly structure-dependent. ${ }^{5}$

Figure 5 shows negative ion mass spectra of $1 \mathrm{mM} \gamma-\mathrm{T}, \mathrm{TL}$, $\mathrm{D}-\mathrm{L}$, or $\alpha-\mathrm{P}+0.2 \mathrm{mM} \mathrm{NaCl}$ in $\mathrm{W}: \mathrm{AN}(1: 4=$ vol:vol) solution microjets in the absence and presence of $\mathrm{O}_{3}(\mathrm{~g})$. The $\mathrm{HH}$ products are detected as the chloride-adducts at $\mathrm{m} / z$ 237;239 in all tested monoterpenes (Figure 5), as confirmed by corresponding $+2 \mathrm{Da}$ shift in both $\mathrm{D}_{2} \mathrm{O}: \mathrm{AN}$ and $\mathrm{H}_{2}{ }^{18} \mathrm{O}$ :AN experiments (Figures $\mathrm{S} 4$ and $\mathrm{S} 5$ ). It is apparent that the production of $\mathrm{HH}$ from CIs $+\left(\mathrm{H}_{2} \mathrm{O}\right)_{n}$ is a major reaction path in all the tested monoterpenes, but its extent significantly differs among these species. The spectra zooming-in on the minor products are shown in Figure S6. The possible reaction mechanisms on the formation of $\mathrm{HH}$ and the minor products are shown in Schemes S3-S6. The characteristic minor products indicate that the structure of the monoterpene plays a major role in their formation. For example, the interfacial ozonolysis of TL produces a $m / z 211 ; 213$ as a minor species, which is assigned to the chloride adduct of the $\mathrm{C}_{7} \mathrm{HH}$ generated from the attack of $\mathrm{O}_{3}$ to the exo-C $=\mathrm{C}$ bond (Scheme S4). The signal intensity of the $\mathrm{C}_{7} \mathrm{HH}$ product is $\sim 17$ times smaller than that of $\mathrm{C}_{10} \mathrm{HH}(\mathrm{m} / z 237 ; 239)$ generated from the attack of $\mathrm{O}_{3}$ to the endo-C $=\mathrm{C}$ bond (Figures 5 and S6). This is in marked contrast with the proposed mechanism of TL ozonolysis in the gas-phase, which suggests that the attack of $\mathrm{O}_{3}$ to the exo-C $=\mathrm{C}$ bond is the dominant channel. ${ }^{55}$ 


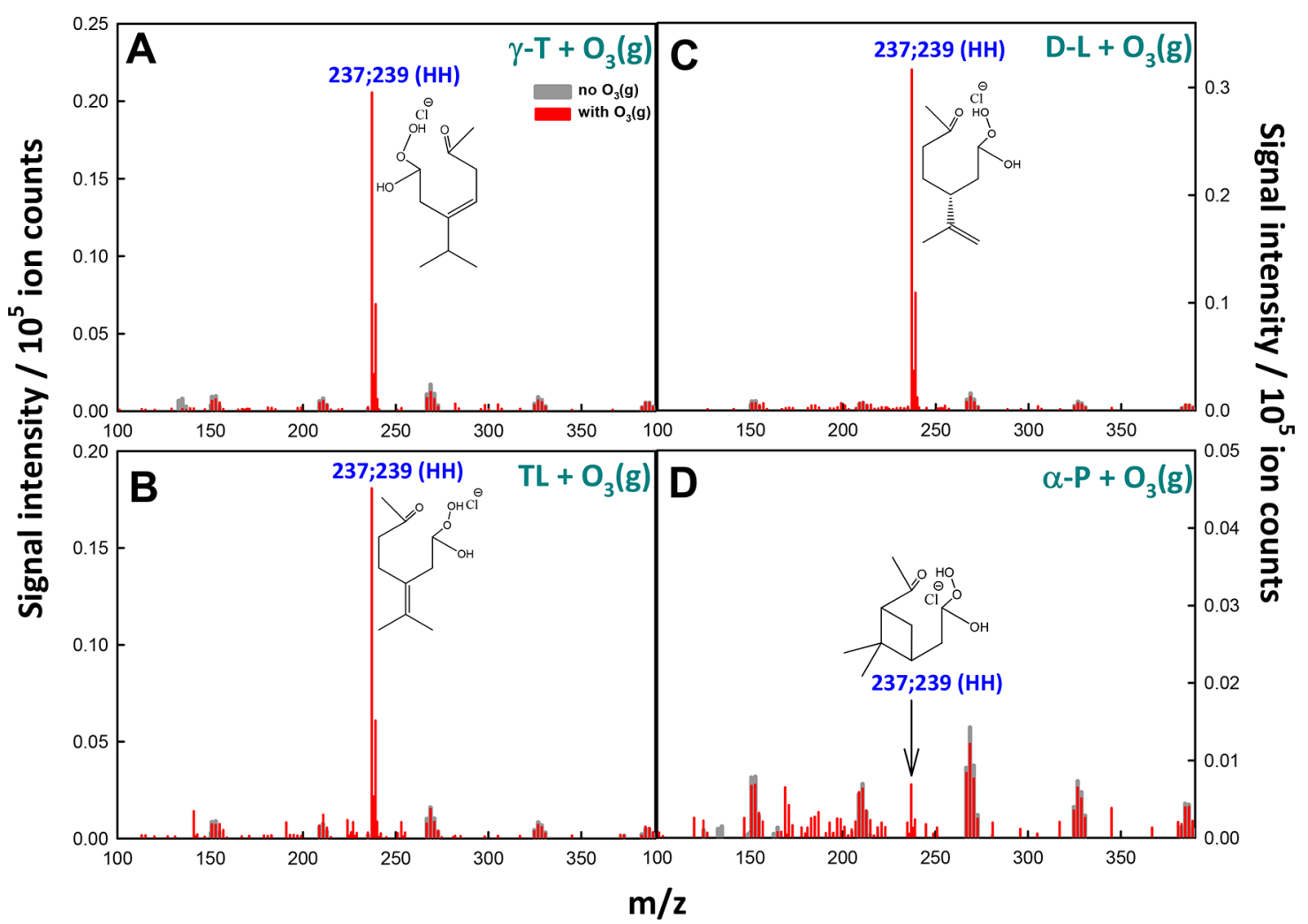

Figure 5. Negative ion mass spectra of $1 \mathrm{mM} \gamma$-terpinene (A), terpinolene (B), D-limonene (C) or $\alpha$-pinene (D) $+0.2 \mathrm{mM} \mathrm{NaCl}$ in W:AN (1:4 = vol:vol) solution microjets (gray), or those exposed to $\mathrm{O}_{3}(\mathrm{~g})\left(\right.$ red, $E \approx 5.2 \times 10^{11}$ molecules $\mathrm{cm}^{-3} \mathrm{~s}$ ) at 1 atm and $298 \mathrm{~K}$. The $\mathrm{m} / z 237 ; 239$ signals correspond to chloride-adducts of $\alpha$-hydroxy hydroperoxides (HH). Representative structures of the $\mathrm{HH}-\mathrm{Cl}^{-}$adducts are shown among possible isomers.

Relative $\mathrm{HH}$ signal intensities for the different monoterpenes under the same experimental conditions are shown in Figure 6. The observed relative yields of $\mathrm{HH}$ production are in the order of: $\alpha$-T $(1.00) \gg \mathrm{D}-\mathrm{L}(0.18)>\gamma$-T $(0.11) \sim \mathrm{TL}$ $(0.10) \gg \alpha$-P (0.01). The exceptional reactivity of $\alpha$-T may be associated with its unique pair of conjugated endo $\mathrm{C}=\mathrm{C}$ double bonds among this set of monoterpenes (Figure 1). Only $\alpha$-T CI possesses a vinyl moiety, which is therefore

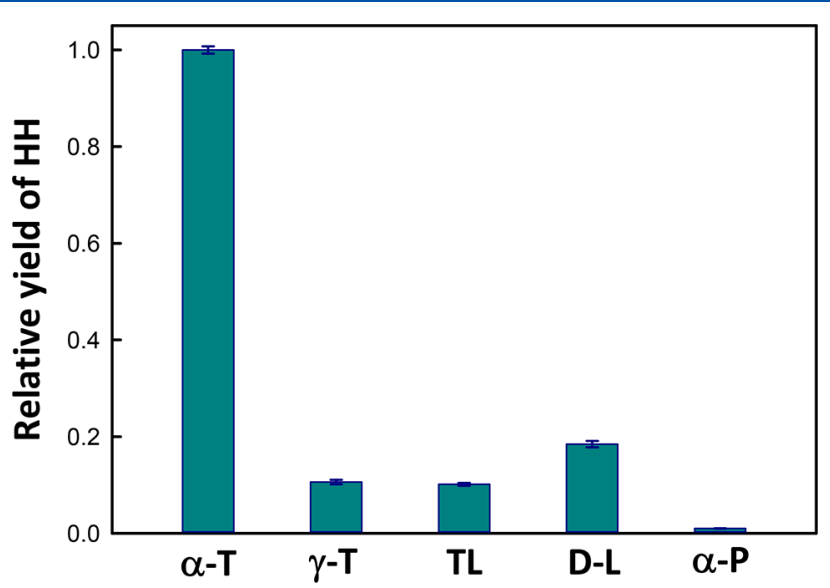

Figure 6. Relative yields of hydroxy-hydroperoxides $(\mathrm{HH}, \mathrm{m} / \mathrm{z}$ 237;239) from $1 \mathrm{mM} \alpha$-terpinene, $\gamma$-terpinene, terpinolene, Dlimonene, or $\alpha$-pinene $+0.2 \mathrm{mM} \mathrm{NaCl}$ in W:AN $(1: 4=$ vol:vol $)$ solution microjets exposed to $\mathrm{O}_{3}(\mathrm{~g})\left(E \approx 5.2 \times 10^{11}\right.$ molecules $\mathrm{cm}^{-3}$ s) at $1 \mathrm{~atm}$ and $298 \mathrm{~K}$. See text for details. Error bars are derived from three measurements. expected to display a unique reactivity among the other monoterpenes. In fact, a very recent study shows that the methyl vinyl ketone oxide derived from the ozonolysis of isoprene (a 1,3-diene) in the gas-phase has unexpected reactivity. ${ }^{56}$ The production of $\mathrm{HH}$ depends on at least two factors: (1) monoterpene ozonolysis rates, and (2) relative rates of CIs isomerization/decomposition vs reaction with $\left(\mathrm{H}_{2} \mathrm{O}\right)_{n}$ at the gas-liquid interface. Since $\mathrm{HH}$ productions as a function of $E\left(\mathrm{O}_{3}\right)$ (Figure 4 and Figure S7) are specific to each monoterpene, both factors could play a role. As a reference, the reported gas-phase rate constants of ozonolyses are $k\left(\alpha-\mathrm{T}+\mathrm{O}_{3}\right)$ $\approx 2 \times 10^{-14}, k\left(\gamma-\mathrm{T}+\mathrm{O}_{3}\right) \approx 1 \times 10^{-16}, k\left(\mathrm{TL}+\mathrm{O}_{3}\right) \approx 2 \times 10^{-15}$, $k\left(\mathrm{D}-\mathrm{L}+\mathrm{O}_{3}\right) \approx 2 \times 10^{-16}, k\left(\alpha-\mathrm{P}+\mathrm{O}_{3}\right) \approx 1 \times 10^{-16} \mathrm{~cm}^{3}$ molecule $\mathrm{s}^{-1} \mathrm{~s}^{-1} \cdot 2,57 \mathrm{~A}$ caveat is in order at this point. We had found that the interfacial ozonolysis of the sesquiterpene $\beta$-caryophyllene proceeds $\sim 20$ times faster than in the bulk liquid saturated with ozone, and orders of magnitude faster than in the gas-phase under the same concentration of $\mathrm{O}_{3}(\mathrm{~g}) .{ }^{18,37}$ If ozonolysis rates followed the same trend in gas-phase and at air-liquid interfaces, the high yield of $\mathrm{HH}$ in the case of $\alpha$-T would be consistent with the high value of its ozonolysis rates. The correlation between $\mathrm{HH}$ yields and ozonolysis rates, however, does not extend to the other monoterpenes. The exceptionally small yield of $\mathrm{HH}$ from the ozonolysis of $\alpha$-P is in accordance with a theoretical prediction on the gas-phase reactivity of the $\alpha$-P CI, whose reaction rate constants with $\mathrm{H}_{2} \mathrm{O}$ and $\left(\mathrm{H}_{2} \mathrm{O}\right)_{2}$ are much smaller than that of its unimolecular decomposition. ${ }^{5}$ The unexpectedly large yield of $\mathrm{HH}$ for $\mathrm{D}-\mathrm{L}$ is worth noting, given that $\mathrm{D}-\mathrm{L}$ is one of the most abundant monoterpenes in the atmosphere. We expect 
the surface affinities of the different monoterpenes and derived CIs and $\mathrm{HH}$ to be similar due to their identical masses and similar functionalities. Their orientations at the surface, however, could be different and depend on the structure, a factor that could play a critical role in interfacial CIs chemistry. As shown below, the dependence of reactivity on the structure of monoterpene CIs is manifested not only toward water molecules but also toward organic acids.

Finally, we investigated the reactions of monoterpene CIs with atmospherically relevant organic acids. Figure 7 shows

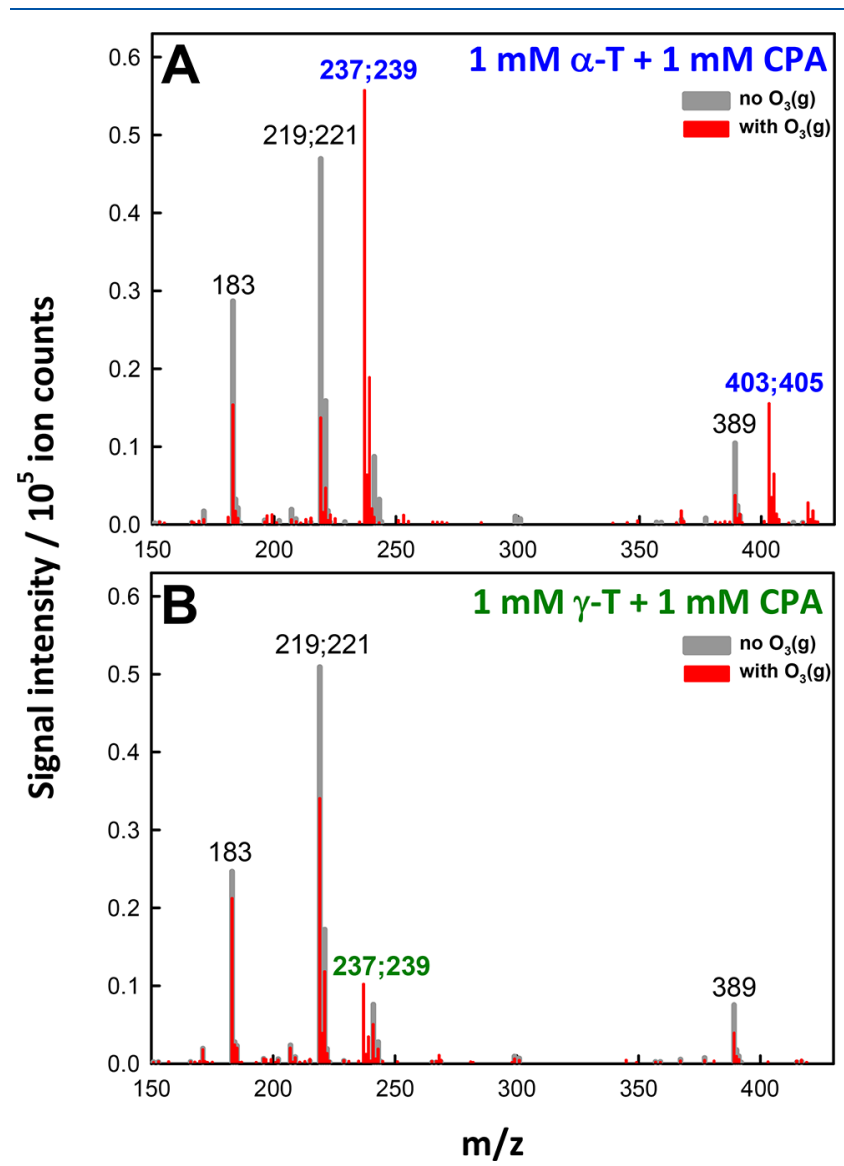

Figure 7. Negative ion mass spectrum of $1 \mathrm{mM} \alpha$-terpinene (A) or 1 $\mathrm{mM} \gamma$-terpinene (B) $+0.2 \mathrm{mM} \mathrm{NaCl}+1 \mathrm{mM}$ cis-pinonic acid in W:AN (1:4 = vol:vol) solution microjets (gray), or those exposed to $\mathrm{O}_{3}(\mathrm{~g})\left(\mathrm{red}, E \approx 5.3 \times 10^{11}\right.$ molecules $\mathrm{cm}^{-3} \mathrm{~s}$ ) at $1 \mathrm{~atm}$ and $298 \mathrm{~K}$.

negative ion mass spectra of $1 \mathrm{mM} \alpha$-T vs $1 \mathrm{mM} \gamma$-T $+0.2 \mathrm{mM}$ $\mathrm{NaCl}+1 \mathrm{mM}$ cis-pinonic acid (CPA), a major product of the atmospheric oxidation of monoterpenes, ${ }^{17,40,58}$ in W:AN (1:4 $=$ vol:vol) solution microjets in the absence and presence of $\mathrm{O}_{3}(\mathrm{~g})$.

The signals at $m / z 183,219 ; 221$, and 389 appearing in the absence of $\mathrm{O}_{3}(\mathrm{~g})$ are assigned to $\mathrm{CPA}^{-},(\mathrm{CPA}) \mathrm{Cl}^{-}$, and $\mathrm{Na}(\mathrm{CPA})_{2}{ }^{-}$, respectively. ${ }^{17}$ In Figure $7 \mathrm{~A}$, new mass signals at $\mathrm{m} / z 403 ; 405$ in addition to those at $\mathrm{m} / \mathrm{z} 237 ; 239$ appear during the interfacial ozonolysis of $\alpha$-T in the presence of CPA. The $m / z 403 ; 405$ product is assigned to the chloride adduct of $\alpha$-acyloxy hydroperoxides $\left(\mathrm{C}_{20}\right.$ ester hydroperoxides $)$ generated by CPA addition to $\alpha$-T CIs at the gas-liquid interface: $m / z=136(\alpha-\mathrm{T})+48\left(\mathrm{O}_{3}\right)+184(\mathrm{CPA})+35 ; 37\left(\mathrm{Cl}^{-}\right)=$ $403 ; 405$. As far as we know, this is the first report on the formation of $\alpha$-acyloxy-hydroperoxides from the reaction of monoterpene CIs with CPA at the gas-liquid interface. Mass spectral signals derived from $1 \mathrm{mM} \alpha-\mathrm{T}+0.2 \mathrm{mM} \mathrm{NaCl}+10$ $\mathrm{mM}$ CPA in W:AN (1:4 = vol:vol) microjets exposed to gaseous $\mathrm{O}_{3} / \mathrm{O}_{2}$ mixtures as functions of $E\left(\mathrm{O}_{3}\right)$ (Figure S8) show that $\alpha$-T CIs competitively react with $\left(\mathrm{H}_{2} \mathrm{O}\right)_{n}$ and CPA at the gas-liquid interface. Remarkably, the ozonolysis of $\gamma$-T with CPA under the same conditions does not give rise to $\mathrm{m} / z$ $403 ; 405$ signals (Figure 7B). The same observation applies to the ozonolysis of TL, D-L, and $\alpha$-P with $1 \mathrm{mM} \mathrm{CPA}$ (Figure S9). Thus, only $\alpha$-T CIs are scavenged by CPA on aqueous surfaces. The marked contrast of these findings with previous experiments that showed CPA is an exceptionally efficient scavenger of sesquiterpene ( $\beta$-caryophyllene and $\alpha$-humulene) CIs on aqueous organic surfaces, ${ }^{17,59}$ underscores the fact that CIs reactivity is critically affected by their structures ${ }^{6}$ and, possibly, also by the orientations of $\mathrm{CIs}$ at the gas-liquid interface. $^{20,21}$ The effect of the orientation of reactants on CIs interfacial reactions is manifested by the relative inertness of $\beta$ caryophyllene CIs toward benzoic acid (BA). ${ }^{60}$ The amphiphilic nature of BA places the aromatic ring closer to the air-water interface while leaving the reactive $-\mathrm{C}(\mathrm{O}) \mathrm{OH}$ group buried deeper in the liquid. ${ }^{60}$

We also investigated the reaction of monoterpene CIs with octanoic acid (OA), a surface-active $n$-alkanoic acid. Negative ion mass spectra of $1 \mathrm{mM} \alpha$-T $+0.2 \mathrm{mM} \mathrm{NaCl}+5 \mathrm{mM}$ OA in $\mathrm{W}: \mathrm{AN}(1: 4=\mathrm{vol}: \mathrm{vol})$ solution microjets in the absence or presence of $\mathrm{O}_{3}(\mathrm{~g})$ (Figure $\mathrm{S} 10$ ) shows the formation of the $\mathrm{m} /$ $z$ 363;365 product, $\mathrm{C}_{18}$ ester hydroperoxides from CIs + OA, in contrast with the absence of the corresponding product for other monoterpenes (Figure S11). Again, only $\alpha$-T CIs react with $\mathrm{OA}$ on aqueous surfaces, while other monoterpene CIs are inert toward $\mathrm{OA}$.

These results imply the reactions of $\gamma$-T, TL, D-L, and $\alpha$-P monoterpene CIs with these acids are much slower than those with water molecules and/or their unimolecular isomerizations/decompositions under the present condition. Although structural effects on the reactivity of small $\left(\mathrm{C}_{\leq 3}\right)$ CIs in the gas-phase are well documented, ${ }^{6,7,61}$ there is little experimental information on the reactivity of the larger, more atmospherically relevant CIs generated from monoterpenes. ${ }^{5,20,62}$ The present study experimentally demonstrates the critical effects of subtle structural and orientational differences on the reactivity of large CIs at the gas-liquid interface for the first time.

Atmospheric Implications. Present results reveal hitherto unrecognized key structural effects on monoterpene CIs reactivities at aqueous interfaces. The relative yields of $\alpha$ hydroxy hydroperoxides vs ester hydroperoxides depend dramatically on the structure of the monoterpenes used in this study, and could not have been predicted from their gasphase ozonolysis rate constants. The inertness of most monoterpene CIs vs the high reactivity of the CI derived from $\alpha$-terpinene toward carboxylic acids will influence their contributions to the generation of high molecular weight polymers and, hence, to the growth of atmospheric particles. We suggest that the unique interfacial chemistry of CIs revealed by our study should be incorporated along with their gas-phase pathways.

\section{CONCLUSION}

Our experiments show that Criegee intermediates produced by ozonolysis of representative monoterpenes ( $\alpha$-terpinene, $\gamma$ terpinene, terpinolene, D-limonene, and $\alpha$-pinene) react with $\left(\mathrm{H}_{2} \mathrm{O}\right)_{n}$ to form hydroxy-hydroperoxides $(\mathrm{HH})$ in the 
interfacial layers of model aqueous organic aerosols. Massspecific identification of the products/intermediates within a very short $(<10 \mu \mathrm{s})$ reaction time enables us to elucidate the reaction mechanisms. Present results show that $\mathrm{HH}$ are dominant products during the interfacial ozonolysis of monoterpenes in the absence of other hydroxylic species, and that their formation largely depends on the monoterpene structure. Intriguingly, we found that only $\alpha$-T CIs are scavenged by $\mathrm{CPA}$ or $\mathrm{OA}$ on aqueous surfaces, suggesting that reactions of monoterpene CIs with $\left(\mathrm{H}_{2} \mathrm{O}\right)_{n}$ and organic acids and the isomerizations/decompositions at air-liquid interfaces are critically dependent on their molecular structures.

\section{ASSOCIATED CONTENT}

\section{S Supporting Information}

The Supporting Information is available free of charge on the ACS Publications website at DOI: 10.1021/acs.jpca.8b06914. Additional experimental data (PDF)

\section{AUTHOR INFORMATION}

\section{Corresponding Author}

*(S.E.) E-mail: enami.shinichi@nies.go.jp. Telephone: +81-29850-2770.

\section{ORCID}

Shinnosuke Ishizuka: 0000-0002-5915-3576

Agustín J. Colussi: 0000-0002-3400-4101

Shinichi Enami: 0000-0002-2790-7361

\section{Author Contributions}

S.E. designed the research; J.Q. performed experiments; S.E. contributed new reagents/analytic tools; J.Q., S.I., K.T., A.J.C., and S.E. analyzed data and wrote the paper.

\section{Notes}

The authors declare no competing financial interest.

\section{ACKNOWLEDGMENTS}

S.E. is grateful to the JSPS KAKENHI Grant No. $15 \mathrm{H} 05328$. A.J.C. acknowledges funding from the National Science Foundation under Grant AGS-1744353.

\section{REFERENCES}

(1) Guenther, A. B.; Jiang, X.; Heald, C. L.; Sakulyanontvittaya, T.; Duhl, T.; Emmons, L. K.; Wang, X. The Model of Emissions of Gases and Aerosols from Nature Version 2.1 (MEGAN2.1): An Extended and Updated Framework for Modeling Biogenic Emissions. Geosci. Model Dev. 2012, 5, 1471-1492.

(2) Seinfeld, J. H.; Pandis, S. N. Atmospheric Chemistry and Physics: From Air Pollution to Climate Change, 2nd ed.; Wiley: Hoboken, NJ, 2006.

(3) Criegee, R. Mechanism of Ozonolysis. Angew. Chem., Int. Ed. Engl. 1975, 14, 745-752.

(4) Osborn, D. L.; Taatjes, C. A. The Physical Chemistry of Criegee Intermediates in the Gas Phase. Int. Rev. Phys. Chem. 2015, 34, 309360.

(5) Vereecken, L.; Novelli, A.; Taraborrelli, D. Unimolecular Decay Strongly Limits the Atmospheric Impact of Criegee Intermediates. Phys. Chem. Chem. Phys. 2017, 19, 31599-31612.

(6) Jr-Min Lin, J.; Chao, W. Structure-Dependent Reactivity of Criegee Intermediates Studied with Spectroscopic Methods. Chem. Soc. Rev. 2017, 46, 7483-7497.

(7) Lester, M. I.; Klippenstein, S. J. Unimolecular Decay of Criegee Intermediates to $\mathrm{OH}$ Radical Products: Prompt and Thermal Decay Processes. Acc. Chem. Res. 2018, 51, 978-985.
(8) Hatakeyama, S.; Akimoto, H. Reactions of Criegee Intermediates in the Gas-Phase. Res. Chem. Intermed. 1994, 20, 503-524.

(9) Sakamoto, Y.; Yajima, R.; Inomata, S.; Hirokawa, J. Water Vapour Effects on Secondary Organic Aerosol Formation in Isoprene Ozonolysis. Phys. Chem. Chem. Phys. 2017, 19, 3165-3175.

(10) Nguyen, T. B.; et al. Atmospheric Fates of Criegee Intermediates in the Ozonolysis of Isoprene. Phys. Chem. Chem. Phys. 2016, 18, 10241-10254.

(11) Yao, L.; Ma, Y.; Wang, L.; Zheng, J.; Khalizov, A.; Chen, M. D.; Zhou, Y. Y.; Qi, L.; Cui, F. P. Role of Stabilized Criegee Intermediate in Secondary Organic Aerosol Formation from the Ozonolysis of Alpha-Cedrene. Atmos. Environ. 2014, 94, 448-457.

(12) Taatjes, C. A.; Shallcross, D. E.; Percival, C. J. Research Frontiers in the Chemistry of Criegee Intermediates and Tropospheric Ozonolysis. Phys. Chem. Chem. Phys. 2014, 16, 1704-1718.

(13) Tadayon, S. V.; Foreman, E. S.; Murray, C. Kinetics of the Reactions between the Criegee Intermediate $\mathrm{CH}_{2} \mathrm{OO}$ and Alcohols. J. Phys. Chem. A 2018, 122, 258-268.

(14) Khan, M. A. H.; Percival, C. J.; Caravan, R. L.; Taatjes, C. A.; Shallcross, D. E. Criegee Intermediates and Their Impacts on the Troposphere. Environ. Sci. Processes Impacts 2018, 20, 437-453.

(15) Enami, S.; Hoffmann, M. R.; Colussi, A. J. Criegee Intermediates React with Levoglucosan on Water. J. Phys. Chem. Lett. 2017, 8, 3888-3894.

(16) Enami, S.; Colussi, A. J. Reactions of Criegee Intermediates with Alcohols at Air-Aqueous Interfaces. J. Phys. Chem. A 2017, 121, 5175-5182.

(17) Enami, S.; Colussi, A. J. Efficient Scavenging of Criegee Intermediates on Water by Surface-Active cis-Pinonic Acid. Phys. Chem. Chem. Phys. 2017, 19, 17044-17051.

(18) Enami, S.; Colussi, A. J. Criegee Chemistry on Aqueous Organic Surfaces. J. Phys. Chem. Lett. 2017, 8, 1615-1623.

(19) Zhong, J.; Kumar, M.; Francisco, J. S.; Zeng, X. C. Insight into Chemistry on Cloud/Aerosol Water Surfaces. Acc. Chem. Res. 2018, 51, 1229-1237.

(20) Zhong, J.; Kumar, M.; Zhu, C. Q.; Francisco, J. S.; Zeng, X. C. Surprising Stability of Larger Criegee Intermediates on Aqueous Interfaces. Angew. Chem., Int. Ed. 2017, 56, 7740-7744.

(21) Zhu, C. Q.; Kumar, M.; Zhong, J.; Li, L.; Francisco, J. S.; Zeng, X. C. New Mechanistic Pathways for Criegee-Water Chemistry at the Air/Water Interface. J. Am. Chem. Soc. 2016, 138, 11164-11169.

(22) Atkinson, R.; Arey, J. Gas-Phase Tropospheric Chemistry of Biogenic Volatile Organic Compounds: A Review. Atmos. Environ. 2003, 37, S197-S219.

(23) Enami, S.; Hoffmann, M. R.; Colussi, A. J. Dry Deposition of Biogenic Terpenes via Cationic Oligomerization on Environmental Aqueous Surfaces. J. Phys. Chem. Lett. 2012, 3, 3102-3108.

(24) Liggio, J.; Li, S. M.; Brook, J. R.; Mihele, C. Direct Polymerization of Isoprene and Alpha-Pinene on Acidic Aerosols. Geophys. Res. Lett. 2007, 34, L05814.

(25) Connelly, B. M.; Tolbert, M. A. Reaction of Isoprene on Thin Sulfuric Acid Films: Kinetics, Uptake, and Product Analysis. Environ. Sci. Technol. 2010, 44, 4603-4608.

(26) Ishizuka, S.; Fujii, T.; Matsugi, A.; Sakamoto, Y.; Hama, T.; Enami, S. Controlling Factors of Oligomerization at the Water Surface: Why Is Isoprene Such a Unique VOC? Phys. Chem. Chem. Phys. 2018, 20, 15400-15410.

(27) Enami, S.; Mishra, H.; Hoffmann, M. R.; Colussi, A. J. Protonation and Oligomerization of Gaseous Isoprene on Mildly Acidic Surfaces: Implications for Atmospheric Chemistry. J. Phys. Chem. A 2012, 116, 6027-6032.

(28) Limbeck, A.; Kulmala, M.; Puxbaum, H. Secondary Organic Aerosol Formation in the Atmosphere via Heterogeneous Reaction of Gaseous Isoprene on Acidic Particles. Geophys. Res. Lett. 2003, 30, 19.

(29) Perrine, K. A.; Van Spyk, M. H.; Margarella, A. M.; Winter, B.; Faubel, M.; Bluhm, H.; Hemminger, J. C. Characterization of the Acetonitrile Aqueous Solution/Vapor Interface by Liquid-Jet X-Ray Photoelectron Spectroscopy. J. Phys. Chem. C 2014, 118, 2937829388. 
(30) Makowski, M. J.; Stern, A. C.; Hemminger, J. C.; Tobias, D. J. Orientation and Structure of Acetonitrile in Water at the LiquidVapor Interface: A Molecular Dynamics Simulation Study. J. Phys. Chem. C 2016, 120, 17555-17563.

(31) Mukherjee, D.; Ortiz Rodriguez, L. I.; Hilaire, M. R.; Troxler, T.; Gai, F. 7-Cyanoindole Fluorescence as a Local Hydration Reporter: Application to Probe the Microheterogeneity of Nine Water-Organic Binary Mixtures. Phys. Chem. Chem. Phys. 2018, 20, 2527-2535.

(32) Enami, S.; Sakamoto, Y.; Colussi, A. J. Fenton Chemistry at Aqueous Interfaces. Proc. Natl. Acad. Sci. U. S. A. 2014, 111, 623-628.

(33) Enami, S.; Hoffmann, M. R.; Colussi, A. J. Proton Availability at the Air/Water Interface. J. Phys. Chem. Lett. 2010, 1, 1599-1604.

(34) Enami, S.; Colussi, A. J. Long-Range Hofmeister Effects of Anionic and Cationic Amphiphiles. J. Phys. Chem. B 2013, 117, 62766281 .

(35) Colussi, A. J.; Enami, S. Comment on "Surface Acidity of Water Probed by Free Energy Calculation for Trimethylamine Protonation". J. Phys. Chem. C 2014, 118, 2894-2894.

(36) Mishra, H.; Enami, S.; Nielsen, R. J.; Hoffmann, M. R.; Goddard, W. A.; Colussi, A. J. Anions Dramatically Enhance Proton Transfer through Water Interfaces. Proc. Natl. Acad. Sci. U. S. A. 2012, 109, 10228-10232.

(37) Enami, S.; Hoffmann, M. R.; Colussi, A. J. Prompt Formation of Organic Acids in Pulse Ozonation of Terpenes on Aqueous Surfaces. J. Phys. Chem. Lett. 2010, 1, 2374-2379.

(38) Hirabayashi, A.; Sakairi, M.; Koizumi, H. Sonic Spray Ionization Method for Atmospheric-Pressure Ionization MassSpectrometry. Anal. Chem. 1994, 66, 4557-4559.

(39) Enami, S.; Colussi, A. J. Long-Range Specific Ion-Ion Interactions in Hydrogen-Bonded Liquid Films. J. Chem. Phys. 2013, 138, 184706 .

(40) Enami, S.; Sakamoto, Y. OH-Radical Oxidation of SurfaceActive cis-Pinonic Acid at the Air-Water Interface. J. Phys. Chem. A 2016, 120, 3578-3587.

(41) Zhao, R.; Kenseth, C. M.; Huang, Y.; Dalleska, N. F.; Seinfeld, J. H. Iodometry-Assisted Liquid Chromatography Electrospray Ionization Mass Spectrometry for Analysis of Organic Peroxides: An Application to Atmospheric Secondary Organic Aerosol. Environ. Sci. Technol. 2018, 52, 2108-2117.

(42) Zhao, R.; Kenseth, C. M.; Huang, Y.; Dalleska, N. F.; Kuang, X. M.; Chen, J.; Paulson, S. E.; Seinfeld, J. H. Rapid Aqueous-Phase Hydrolysis of Ester Hydroperoxides Arising from Criegee Intermediates and Organic Acids. J. Phys. Chem. A 2018, 122, 5190-5201.

(43) Zhou, S. M.; Rivera-Rios, J. C.; Keutsch, F. N.; Abbatt, J. P. D. Identification of Organic Hydroperoxides and Peroxy Acids Using Atmospheric Pressure Chemical Ionization-Tandem Mass Spectrometry (APCI-MS/MS): Application to Secondary Organic Aerosol. Atmos. Meas. Tech. 2018, 11, 3081-3089.

(44) Sakamoto, Y.; Inomata, S.; Hirokawa, J. Oligomerization Reaction of the Criegee Intermediate Leads to Secondary Organic Aerosol Formation in Ethylene Ozonolysis. J. Phys. Chem. A 2013, 117, 12912-12921.

(45) Tong, H.; Arangio, A. M.; Lakey, P. S. J.; Berkemeier, T.; Liu, F.; Kampf, C. J.; Brune, W. H.; Pöschl, U.; Shiraiwa, M. Hydroxyl Radicals from Secondary Organic Aerosol Decomposition in Water. Atmos. Chem. Phys. 2016, 16, 1761-1771.

(46) Vidrio, E.; Phuah, C. H.; Dillner, A. M.; Anastasio, C. Generation of Hydroxyl Radicals from Ambient Fine Particles in a Surrogate Lung Fluid Solution. Environ. Sci. Technol. 2009, 43, 922927.

(47) Shiraiwa, M.; et al. Aerosol Health Effects from Molecular to Global Scales. Environ. Sci. Technol. 2017, 51, 13545-13567.

(48) Enami, S.; Hoffmann, M. R.; Colussi, A. J. OH-Radical Specific Addition to Glutathione S-Atom at the Air-Water Interface: Relevance to the Redox Balance of the Lung Epithelial Lining Fluid. J. Phys. Chem. Lett. 2015, 6, 3935-3943.

(49) Redington, R. L. Kinetics of Oxygen-18 Exchange between Carboxylic Acids and Water. J. Phys. Chem. 1976, 80, 229-235.
(50) Heine, N.; Houle, F. A.; Wilson, K. R. Connecting the Elementary Reaction Pathways of Criegee Intermediates to the Chemical Erosion of Squalene Interfaces During Ozonolysis. Environ. Sci. Technol. 2017, 51, 13740-13748.

(51) Mackenzie-Rae, F. A.; Karton, A.; Saunders, S. M. Computational Investigation into the Gas-Phase Ozonolysis of the Conjugated Monoterpene $\alpha$-Phellandrene. Phys. Chem. Chem. Phys. 2016, 18, 27991-28002.

(52) Enami, S.; Hoffmann, A. R.; Colussi, A. J. Ozonolysis of Uric Acid at the Air/Water Interface. J. Phys. Chem. B 2008, 112, 41534156.

(53) Chang, Y.-P.; Chang, H.-H.; Lin, J. J.-M. Kinetics of the Simplest Criegee Intermediate Reaction with Ozone Studied Using a Mid-Infrared Quantum Cascade Laser Spectrometer. Phys. Chem. Chem. Phys. 2018, 20, 97-102.

(54) Kjaergaard, H. G.; Kurten, T.; Nielsen, L. B.; Jorgensen, S.; Wennberg, P. O. Criegee Intermediates React with Ozone. J. Phys. Chem. Lett. 2013, 4, 2525-2529.

(55) Ma, Y.; Marston, G. Formation of Organic Acids from the GasPhase Ozonolysis of Terpinolene. Phys. Chem. Chem. Phys. 2009, 11, 4198-4209.

(56) Barber, V. P.; Pandit, S.; Green, A. M.; Trongsiriwat, N.; Walsh, P. J.; Klippenstein, S. J.; Lester, M. I. Four-Carbon Criegee Intermediate from Isoprene Ozonolysis: Methyl Vinyl Ketone Oxide Synthesis, Infrared Spectrum, and OH Production. J. Am. Chem. Soc. 2018, 140, 10866.

(57) Sander, S. P., et al., Chemical Kinetics and Photochemical Data for Use in Stratospheric Modeling Supplement to Evaluation 12: Update of Key Reactions Evaluation Number 13; JPL: 2000.

(58) Cheng, Y.; Brook, J. R.; Li, S. M.; Leithead, A. Seasonal Variation in the Biogenic Secondary Organic Aerosol Tracer CisPinonic Acid: Enhancement Due to Emissions from Regional and Local Biomass Burning. Atmos. Environ. 2011, 45, 7105-7112.

(59) Li, X.; Hede, T.; Tu, T.; Leck, C.; Agren, H. Surface-Active cisPinonic Acid in Atmospheric Droplets: A Molecular Dynamics Study. J. Phys. Chem. Lett. 2010, 1, 769-773.

(60) Qiu, J.; Ishizuka, S.; Tonokura, K.; Enami, S. Reactions of Criegee Intermediates with Benzoic Acid at the Gas/Liquid Interface. J. Phys. Chem. A 2018, 122, 6303-6310.

(61) Kidwell, N. M.; Li, H. W.; Wang, X. H.; Bowman, J. M.; Lester, M. I. Unimolecular Dissociation Dynamics of Vibrationally Activated $\mathrm{CH}_{3} \mathrm{COO}$ Criegee Intermediates to OH Radical Products. Nat. Chem. 2016, 8, 509-514.

(62) Long, B.; Bao, J. L.; Truhlar, D. G. Atmospheric Chemistry of Criegee Intermediates: Unimolecular Reactions and Reactions with Water. J. Am. Chem. Soc. 2016, 138, 14409-14422. 